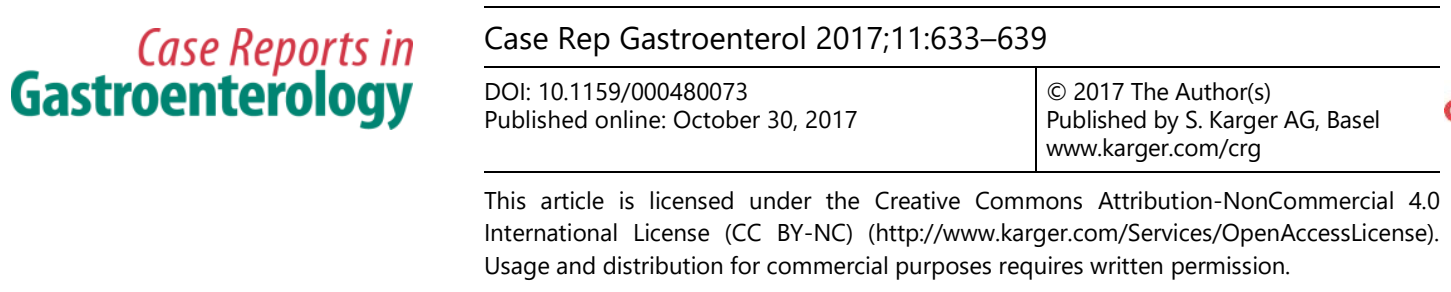

\title{
Massive Upper and Lower GI Bleed from Simultaneous Primary (AL) Amyloidosis of the Stomach and Transverse Colon in a Patient with Multiple Myeloma
}

\author{
Zubair Khan ${ }^{a} \quad$ Umar Darr $^{\mathrm{a}} \quad$ Anas Renno $^{\mathrm{a}} \quad$ Abhinav Tiwari $^{\mathrm{a}} \quad$ Aijaz Sofi $^{\mathrm{a}, \mathrm{b}}$ \\ Ali Nawras ${ }^{a, b}$ \\ aDepartment of Internal Medicine, University of Toledo Medical Center, Toledo, OH, USA; \\ bDivision of Gastroenterology, University of Toledo, Toledo, OH, USA
}

\section{Keywords}

Gastric amyloidosis - Colonic amyloidosis - Gastrointestinal bleed · Primary (AL) amyloidosis . Multiple myeloma

\begin{abstract}
Symptomatic primary (amyloid light-chain or $\mathrm{AL}$ ) amyloidosis of the gastrointestinal (GI) tract is very rare. Most of the patients with symptomatic involvement of the GI tract present with altered motility, malabsorption, or bleeding. We report a case of gastric and colonic amyloidosis on anticoagulation presenting with massive upper and lower Gl bleeding. A 67-yearold lady known to have multiple myeloma and $\mathrm{AL}$ amyloidosis on rivaroxaban presented with massive upper GI bleeding. Esophagogastroduodenoscopy showed a mass lesion $(3 \times 7 \mathrm{~cm})$ located along the greater curvature in the body/antrum with active bleeding. Mucosal biopsies revealed amyloid deposition. She underwent partial gastrectomy and recovered well after surgery, and was discharged home on rivaroxaban. The patient presented again 4 weeks after discharge with bleeding per rectum, and a colonoscopy revealed a large mass in the proximal transverse colon with active bleeding. Biopsy of the mass showed amyloid deposition. At this point, the patient declined any further intervention. Rivaroxaban was discontin-
\end{abstract}


ued, the rectal bleeding stopped, and she was discharged home with no further episodes of GI bleed. Amyloidosis of the GI tract presenting with massive GI bleed is extremely rare and is thought to be related to small-vessel fragility due to amyloid infiltration and impaired hemostasis caused by factor X deficiency. Even though GI bleeding with amyloidosis is spontaneous, use of anticoagulation could activate such episodes in these patients. Caution should be exercised with the use of anticoagulation in patients with amyloidosis involving the $\mathrm{Gl}$ tract, and colonoscopy should be considered in patients with gastric amyloidosis.

(C) 2017 The Author(s)

Published by S. Karger AG, Basel

\section{Introduction}

Primary (amyloid light-chain or AL) amyloidosis of the gastrointestinal (GI) tract is rare, with biopsy-diagnosed disease and clinically apparent disease occurring in 8 and $1 \%$ of patients, respectively [1]. In the GI tract, amyloidosis affects the duodenum most commonly, followed by the stomach and colorectum. GI bleeding due to AL amyloidosis is a rare phenomenon, and has been reported in $10-40 \%$ of patients with GI involvement $[2,3]$. Other clinical manifestations of GI amyloidosis include abdominal pain, gastroesophageal reflux disease-like symptoms, nausea, gastroparesis, food retention, intestinal obstruction (and pseudo-obstruction), malabsorption, bacterial overgrowth, and diarrhea [3]. Such symptoms in patients with known plasma cell dyscrasias should prompt consideration of amyloidosis in the differential diagnosis. Simultaneous gastric and colonic involvement causing substantial upper and lower GI tract bleeding has never been reported in AL amyloidosis.

\section{Case Report}

A 67-year-old lady known to have multiple myeloma and AL amyloidosis presented with massive upper GI bleeding and was admitted to the medical intensive care unit. She was found to have an elevated international normalized ratio of 1.8 and was on rivaroxaban for atrial fibrillation. An emergent esophagogastroduodenoscopy was done, which showed a greater curvature mass at the distal body and proximal antrum with active bleeding. There was a submucosal hematoma around the mass, and the size of the mass was $3 \times 7 \mathrm{~cm}$ (Fig. 1-3).

The patient received 10 units of packed red blood cells for resuscitation from hemorrhagic shock. She underwent angiography of the mesenteric vasculature for arterial embolization. The angiogram was interpreted as normal, and no bleeder could be identified. In the meantime, her hemoglobin level remained stable. The decision was made to proceed with the wedge resection of the mass which was the source of the bleeding, as the patient wished to continue anticoagulation for atrial fibrillation in the future. She underwent partial gastrectomy, and the gastric tissue was sent for histopathological examination. The gastric tissue was found to have amyloid deposition consistent with gastric amyloidosis (Fig. 4).

The patient did well after surgery and was discharged home on rivaroxaban. She presented again 4 weeks after discharge with complaint of bleeding per rectum. Colonoscopy was performed, which revealed a large mass with an overlying clot and fresh bleeding in the proximal transverse colon (Fig. 5).

Biopsy of the mass revealed amyloid deposition. At this point of time, the decision was made to treat her conservatively because of her general condition and wishes. Her hemoglo- 
bin level then remained stable and the bleeding per rectum stopped, so she was discharged home. Upon discharge, rivaroxaban was stopped. She recovered well and had no further episodes of GI bleeding on follow-up.

\section{Discussion}

Amyloidosis is a condition of extracellular fibrillar protein deposition that is commonly associated with tissue injury and dysfunction [4]. Primary amyloidosis usually represents amyloidosis associated with immunocyte dyscrasia from monoclonal proliferation of plasma cells that synthesize an immunoglobulin that is prone to form amyloid. GI amyloidosis can occur as an isolated entity or as part of multisystemic involvement. Different types of amyloid proteins can deposit in various parts of the GI tract or liver, manifesting as abdominal pain, GI dysmotility, diarrhea, GI bleeding, or hepatic injury [5].

Amyloidosis of the GI tract presenting with massive GI bleeding is extremely rare and is thought to be related to small-vessel fragility due to amyloid infiltration and impaired hemostasis caused by factor X deficiency [6]. In the stomach, gastric amyloidosis may have an endoscopic appearance mimicking gastric neoplasia [7, 8], hematomas, erosions and ulcerations, or a nodular gastritis [9]. Amyloidosis of the GI tract can appear as submucosal tumors, polyps, antral narrowing, thickened irregular gastric folds, or loss of rugal folds. Other appearances include gastric ulcers, hematomas, arteriovenous malformations, granularly appearing mucosa, plaque-like lesions, or ulcerative gastritis, often associated with GI bleeding [10].

The pathophysiology of GI bleeding from amyloidosis involves local ischemia, infarction, and mucosal injury which cause erosions, hematomas, or ulcerations. Submucosal hematoma as reported in this case has been described as a distinctive feature of GI amyloidosis on endoscopy and can be seen along the entire length of the GI tract $[3,11]$. The reported size of the hematoma can vary from a few millimeters to several centimeters. Submucosal hematomas can expand rapidly, leading to life-threatening complications. A giant submucosal hematoma of the gastric fundus with rapid expansion resulting in emergent gastrectomy has been reported in the literature [12]. Hematoma rupture in patients with gastric amyloidosis can sometimes cause life-threatening GI bleeding. Endoscopic hemostasis is often ineffective, and other treatment modalities such as surgical intervention or arterial embolization may be needed [13].

Our patient was on anticoagulation, and this was likely to have triggered the GI bleed in her case, since she did not report any further episodes after anticoagulation had been discontinued. Even though GI bleeding in amyloidosis is spontaneous, use of anticoagulation could activate such episodes in these patients. Caution should be exercised with the use of anticoagulation in patients with amyloidosis involving the GI tract. There is no current guideline, but after having found a gastric amyloid lesion, colonoscopy should also be considered for any other amyloid lesion, as was found in our case.

\section{Statement of Ethics}

Approval from an ethics committee was not required in this case, as this is a case report. We have obtained informed consent from the patient to publish this report. 


\section{Case Reports in Gastroenterology}

(c) 2017 The Author(s). Published by S. Karger AG, Basel www.karger.com/crg

Khan et al: Massive Upper and Lower GI Bleed from Simultaneous Primary (AL) Amyloidosis of the Stomach and Transverse Colon in a Patient with Multiple Myeloma

\section{Disclosure Statement}

The authors have no relevant financial or nonfinancial relationships to disclose.

\section{Author Contributions}

Z.K. contributed to writing the case report and major parts of the discussion. U.D. and A.R. assisted in writing the manuscript. A.T. and A.S. assisted in the literature review. A.N. supervised and reviewed the entire article.

\section{References}

1 Menke DM, Kyle RA, Fleming CR, et al: Symptomatic gastric amyloidosis in patients with primary systemic amyloidosis. Mayo Clin Proc 1993;68:763-767.

$\checkmark 2$ Cowan AJ, Skinner M, Seldin DC, et al: Amyloidosis of the gastrointestinal tract: a 13-year, single-center, referral experience. Haematologica 2013;98:141-146.

-3 James DG, Zuckerman GR, Sayuk GS, et al: Clinical recognition of AL type amyloidosis of the luminal gastrointestinal tract. Clin Gastroenterol Hepatol 2007;5:582-588.

4 Gillmore JD, Hawkins PN: Pathophysiology and treatment of systemic amyloidosis. Nat Rev Nephrol 2013;9:574-586.

5 Petre S, Shah IA, Gilani N: Review article: gastrointestinal amyloidosis - clinical features, diagnosis and therapy. Aliment Pharmacol Ther 2008;27:1006-1016.

6 Choufani EB, Sanchorawala V, Ernst T, et al: Acquired factor X deficiency in patients with amyloid light chain amyloidosis: incidence, bleeding manifestations, and response to high-dose chemotherapy. Blood 2001;97:1885-1887.

7 Rivera R, Kaul V, DeCross A, et al: Primary gastric amyloidosis presenting as an isolated gastric mass. Gastrointest Endosc 2012;76:186-187.

8 Björnsson S, Jóhannsson JH, Sigurjónsson F: Localized primary amyloidosis of the stomach presenting with gastric hemorrhage. Acta Med Scand 1987;221:115-119.

$\checkmark 9$ Sawada T, Adachi Y, Akino K, et al: Endoscopic features of primary amyloidosis of the stomach. Endoscopy 2012;44(suppl 2):E275-E276.

-10 Ebert EC, Nagar M: Gastrointestinal manifestations of amyloidosis. Am J Gastroenterol 2008;103: 776-787.

11 Wang CC, Chang MH, Lin CC: A rare cause of gastrointestinal bleeding. Multiple myeloma with extramedullary gastroduodenal plasmacytoma. Gastroenterology 2013;145:e1-e2.

12 Kim SY, Moon SB, Lee SK, et al: Light-chain amyloidosis presenting with rapidly progressive submucosal hemorrhage of the stomach. Asian J Surg 2016;39:113-115.

13 Yeh YC, Lin CH, Huang SC, et al: Education and imaging. Gastrointestinal: gastric hematoma with bleeding in a patient with primary amyloidosis. J Gastroenterol Hepatol 2014;29:419. 


\begin{tabular}{|c|c|c|}
\hline \multirow{3}{*}{$\begin{array}{r}\text { Case Reports in } \\
\text { Gastroenterology }\end{array}$} & \multirow{2}{*}{\multicolumn{2}{|c|}{ Case Rep Gastroenterol 2017;11:633-639 }} \\
\hline & & \\
\hline & DOI: $10.1159 / 000480073$ & $\begin{array}{l}\text { (@) } 2017 \text { The Author(s). Published by S. Karger AG, Basel } \\
\text { www.karger.com/crg }\end{array}$ \\
\hline
\end{tabular}

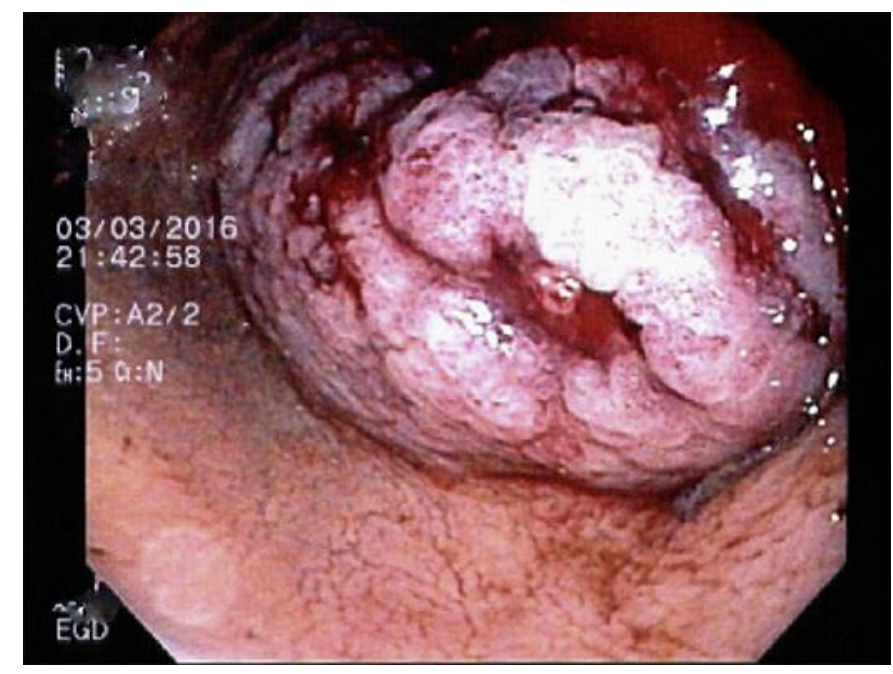

Fig. 1. Esophagogastroduodenoscopic image of the gastric mass.

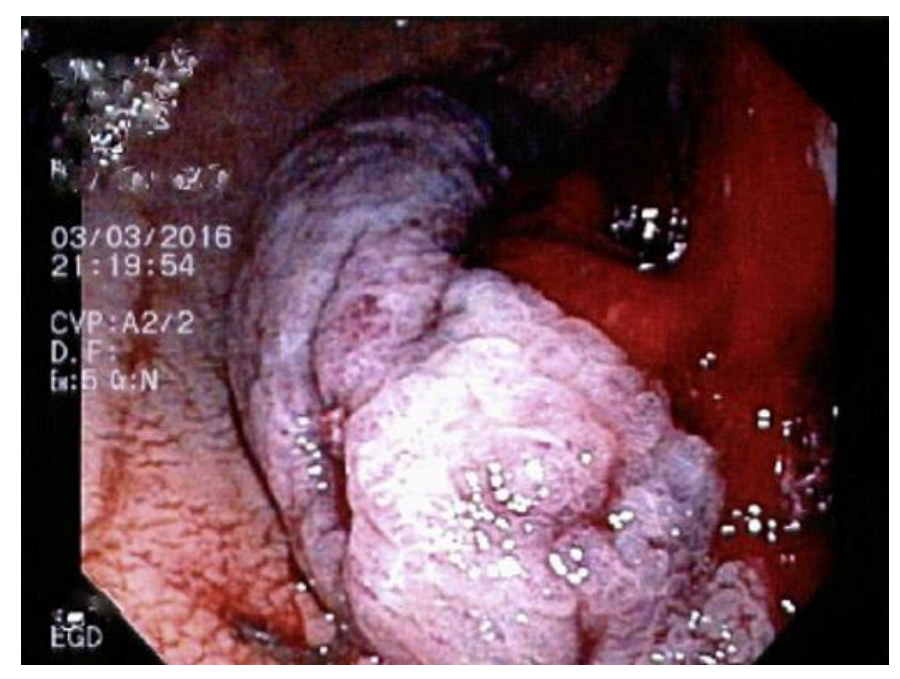

Fig. 2. Esophagogastroduodenoscopic image of the gastric mass with submucosal hemorrhage. 


\section{Case Reports in Gastroenterology}

\begin{tabular}{l|l}
\hline Case Rep Gastroenterol 2017;11:633-639 \\
\hline DOI: 10.1159/000480073 & $\begin{array}{l}\text { @ 2017 The Author(s). Published by S. Karger AG, Basel } \\
\text { www.karger.com/crg }\end{array}$ \\
\hline
\end{tabular}

Khan et al: Massive Upper and Lower GI Bleed from Simultaneous Primary (AL) Amyloidosis of the Stomach and Transverse Colon in a Patient with Multiple Myeloma

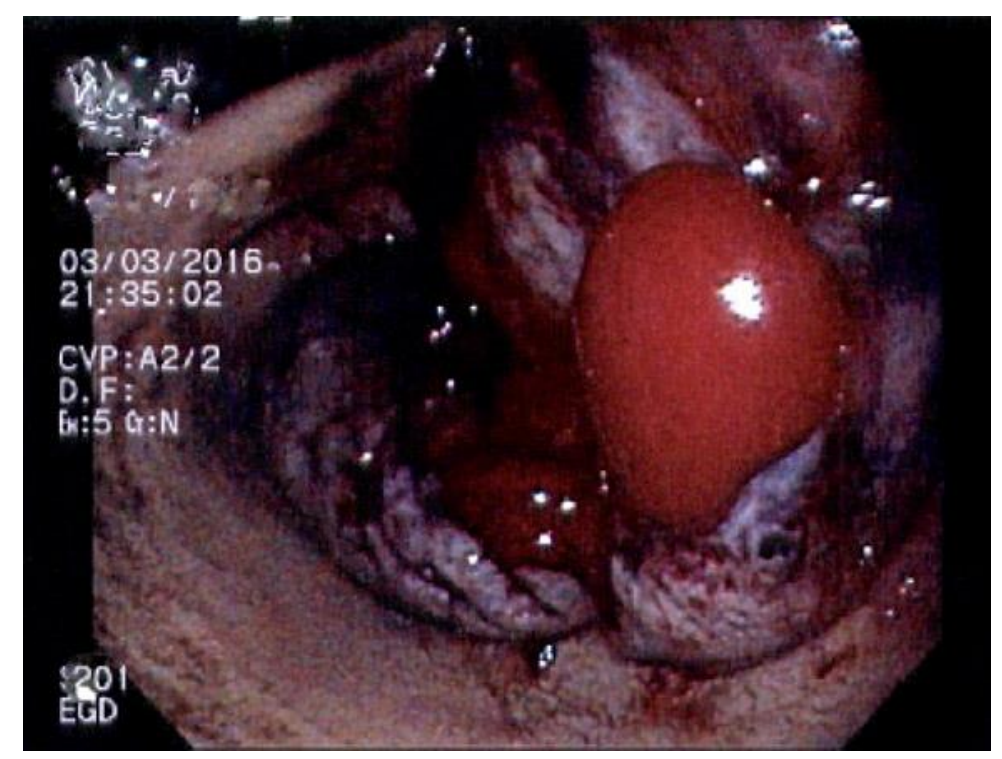

Fig. 3. Another view of the gastric mass with a submucosal hematoma and active bleeding.

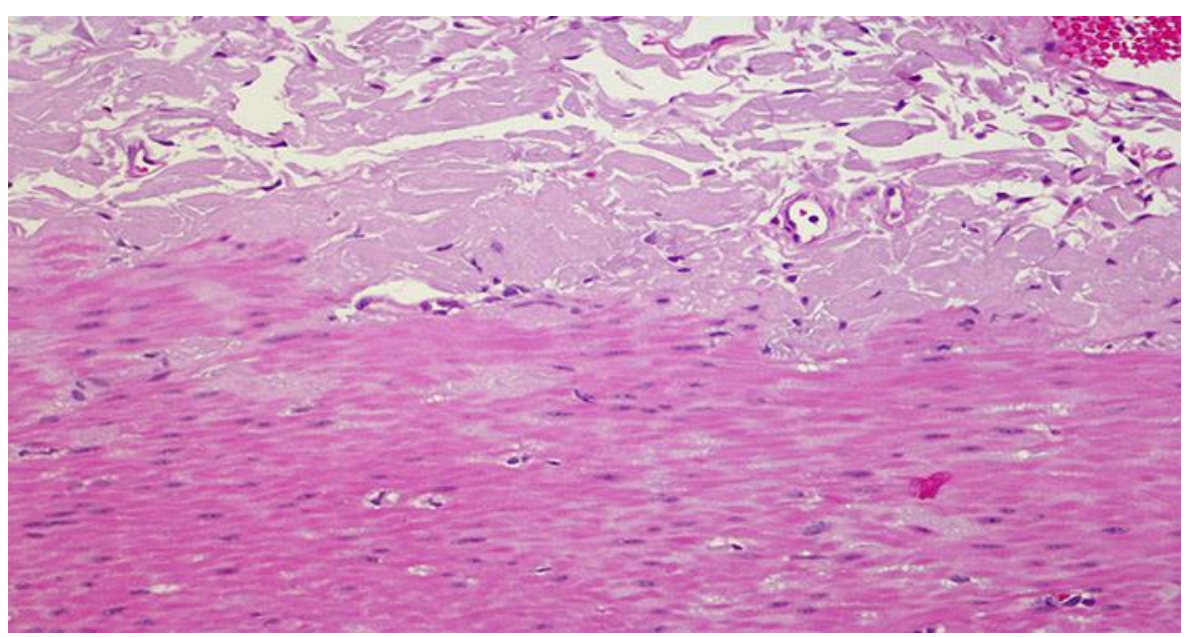

Fig. 4. The muscularis propria is disrupted by an amorphous, weakly eosinophilic, acellular material (amyloid). HE. $\times 200$. 
Khan et al.: Massive Upper and Lower GI Bleed from Simultaneous Primary (AL) Amyloidosis of the Stomach and Transverse Colon in a Patient with Multiple Myeloma

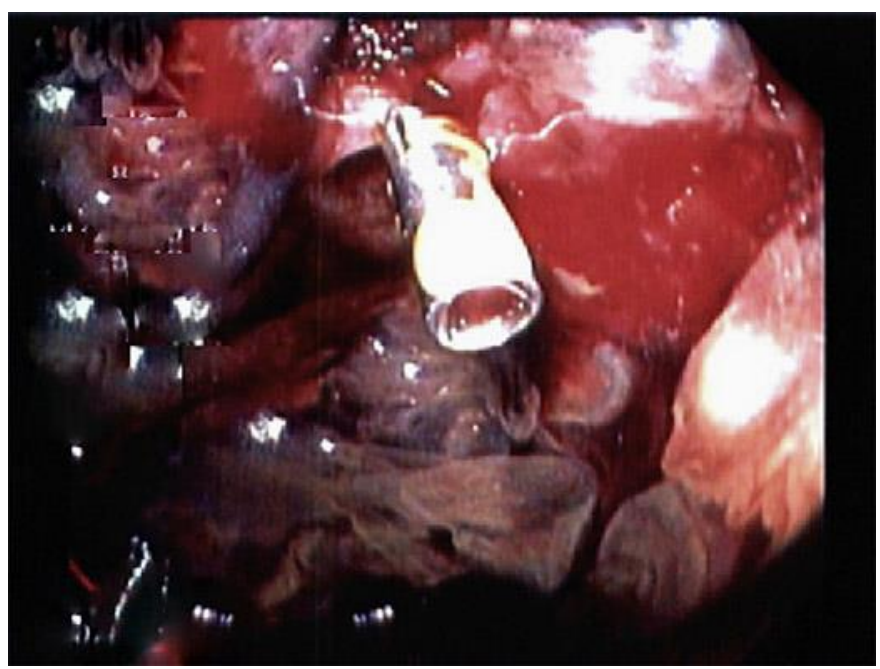

Fig. 5. Colonoscopic image of the transverse colon showing a large bleeding mass with an endoclip. 